NBER WORKING PAPER SERIES

HOT TIP: NOMINAL EXCHANGE RATES AND INFLATION INDEXED BOND
YIELDS

\author{
Richard H. Clarida \\ Working Paper 18726 \\ http://www.nber.org/papers/w18726
}

\author{
NATIONAL BUREAU OF ECONOMIC RESEARCH \\ 1050 Massachusetts Avenue \\ Cambridge, MA 02138 \\ January 2013
}

*C. Lowell Harriss Professor of Economics, Columbia University. This paper was prepared for the Columbia University Conference on Recent Research in International Finance November 16, 2012 and expounds upon and extends Clarida (2012). I would like to thank Ken West and Bob Hodrick as well as seminar participants at the NY and Boston Feds, the Bank of Canada, the Bundesbank, the Bank of England, The Frankfurt Center for Financial Stability, and the Swiss National Bank for comments on earlier drafts. The views expressed herein are those of the author and do not necessarily reflect the views of the National Bureau of Economic Research.

The author has disclosed a financial relationship of potential relevance for this research. Further information is available online at http://www.nber.org/papers/w18726.ack

NBER working papers are circulated for discussion and comment purposes. They have not been peerreviewed or been subject to the review by the NBER Board of Directors that accompanies official NBER publications.

(C) 2013 by Richard H. Clarida. All rights reserved. Short sections of text, not to exceed two paragraphs, may be quoted without explicit permission provided that full credit, including $(\mathbb{C}$ notice, is given to the source. 
Hot Tip: Nominal Exchange Rates and Inflation Indexed Bond Yields

Richard H. Clarida

NBER Working Paper No. 18726

January 2013

JEL No. F3,F31

\begin{abstract}
$\underline{\text { ABSTRACT }}$
This paper derives a structural relationship between the nominal exchange rate, national price levels, and observed yields on long maturity inflation - indexed bonds. This relationship can be interpreted as defining the fair value of the exchange rate that will prevail in any model or real world economy in which inflation indexed bonds are traded. An advantage of our derivation is that it does not require restrictive assumptions on financial market equilibrium to be operational. We take our theory to a dataset spanning the period January 2001 - February 2011 and study a daily, real time decompositions of pound, euro, and yen exchange rates into their fair value and risk premium components. The relative importance of these two factors varies depending on the sub sample studied. However, sub samples in which we find correlations of 0.30 to 0.60 between daily exchange rate changes and daily changes in fair value are not uncommon. We also show empirically and justify theoretically that a 1 percent rise in the foreign currency risk premium is on average contemporaneously associated with a 50 basis point rise in the inflation indexed bond return differential in favor of the foreign country and an 50 basis point appreciation of the dollar
\end{abstract}

\author{
Richard H. Clarida \\ Columbia University \\ 420 West 118th Street \\ Room 1111, IAB \\ New York, NY 10027 \\ and NBER \\ rhc2@columbia.edu
}




\section{Hot TIP: Nominal Exchange Rates and Inflation Indexed Bond Yields}

Richard H. Clarida*

\section{Introduction}

Extending Clarida (2012) this paper derives a structural relationship between the nominal exchange rate, national price levels, and observed yields on long maturity inflation - indexed bonds. This relationship can be interpreted as defining the fair value of the exchange rate that will prevail in any model or real world economy in which inflation indexed bonds are traded. Fair value is the level of the nominal exchange rate that equates the known real return to holding a long maturity home currency inflation indexed bond to the expected real return to holding an inflation indexed bond payable in foreign currency. We derive a novel, empirically observable real time measure of the risk premium (expected excess return on long maturity foreign currency investment in an inflation indexed bond) that can open up a wedge between the observed level of the nominal exchange rate and its fair value and we relate our measure of the long horizon real risk premium to the Fama (1984) measure of the short horizon nominal risk premium. An advantage of our derivation is that it does not require restrictive assumptions (e.g. complete markets, representative agent) on financial market equilibrium to be operational.

We take our theory to a dataset spanning the period January 2001 February 2011 and study high frequency, real time decompositions of pound, euro, and yen exchange rates into their fair value and risk premium components. The relative importance of these two factors varies depending on the sub sample studied. However, sub samples in which we find correlations of 0.30 to 0.60 between daily exchange rate changes and daily changes in fair value are not uncommon. We also show empirically and justify theoretically that a 1 percent rise in the foreign currency risk premium is on average contemporaneously associated with a 50 basis point rise in the inflation indexed bond return differential in favor of the foreign country and an 50 basis point appreciation of the dollar

${ }^{*}$ C. Lowell Harriss Professor of Economics, Columbia University and Research Associate NBER. This paper was prepared for the Columbia University Conference on Recent Research in International Finance November 16, 2012 and expounds upon and extends Clarida (2012). I would like to thank Ken West and Bob Hodrick as well as seminar participants at the NY and Boston Feds, the Bank of Canada, the Bundesbank, the Bank of England, The Frankfurt Center for Financial Stability, and the Swiss National Bank for comments on earlier drafts. 


\section{An Equilibrium Implication}

Consider a US investor who, among the many assets he can hold, can hold inflation indexed sovereign bonds denominated in dollars and pounds. Let $\rho_{t}$ denote the dollar price a zero coupon inflation indexed bond that pays off 1 dollar in $n$ years multiplied by cumulative realized US inflation over the next $n$ years. The realized nominal gross return on this investment, if held to maturity, will be

1) $\quad R^{h h_{t, n}}=\left(1 / \rho_{t}\right) P_{t+n /} P_{t}$

where $P_{t}$ is the CPI. Let $\rho^{*}$ denote the pound price of a zero coupon inflation indexed bond that pays off 1 pound in $n$ years multiplied by cumulative realized UK inflation over the next $n$ years. The realized nominal gross return to a US investor on this investment, if held to maturity, will be

$$
R^{h, f_{t, n}}=\left(1 / S_{t} \rho_{t}^{*}\right) S_{t+n} P_{t+n /}^{*} P_{t}^{*}
$$

Where $S_{t}$ is the dollar price of a pound. The realized real gross return on holding a US inflation indexed bond to maturity is

$$
R^{h h_{t, n}}=R^{h h_{t, n}}\left(P_{t} / P_{t+n}\right)=\left(1 / \rho_{t}\right) \equiv \exp \left(n r_{t, n}\right)
$$

Thus, of course, the US inflation indexed bond offers a known, nonstochastic realized real return $r_{t, n}$ if held to maturity. But what is the realized real return to a US investor of holding a UK inflation indexed bond?

$$
R R^{h f_{t, n}}=R^{h f_{t, n}}\left(P_{t} / P_{t+n}\right)=\left\{\left(1 / S_{t} \rho_{t}^{*}\right)\left(S_{t+n} P_{t+n /}^{*} P_{t}^{*}\right)\right\} P_{t /} P_{t+n}=\exp \left(n r_{t, n}^{*}\right) Q_{t+n} / Q_{t}
$$

where $Q_{t}=S_{t} P^{*} / P_{t}$ is the CPI real exchange rate. For a US investor the UK inflation indexed bond is not riskless if held to maturity: even though ${ }^{*}{ }_{t, n}$ is known, the US investors bears real exchange rate risk. Notice that this is not an assumption: it follows from the nature of the stochastic nominal cash flows to a US investor for holding a UK linker to maturity. 
Define $\exp \theta_{t, n}$ as the ratio of expected real return to a US investor of holding a UK linker versus known real return to a US investor of holding a TIP

$$
\exp \theta_{t, n} \equiv E_{t} R R^{h f_{t, n}} / R R^{h h_{t, n}}=\left(\exp n r_{t, n}^{*} / \exp n r_{t, n}\right) E_{t} Q_{t+n} / Q_{t}
$$

where $E_{t} Q_{t+n}$ is the expected level of the CPI real exchange rate in $\mathrm{n}$ years. When $\theta_{t, n}>(<) 0$ the expected real return to holding the UK linker exceeds (is less than) the known real return to holding the US TIP. Equation (5) has a particularly convenient interpretation when the horizon $n$ is long enough so that $E_{t} Q_{t+n}=Q$, the assumed constant unconditional mean of the real exchange rate defined by long run relative PPP. In this case, multiplying through by $Q_{t}$ and re arranging we see that:

6) $\quad S_{t}=\left(P_{t} / P_{t}^{*}\right) \exp n\left(r_{t, n}^{*}-r_{t, n}\right) Q \exp -\theta_{t, n}$

or

7) $\quad S_{t}=\tilde{S}_{t} \exp -\theta_{t, n}$

Thus period by period, the observed spot exchange rate is the product of the fair value $\tilde{S}_{t}$ - the level of the spot exchange rate that equates the known real return to investing in the US TIP to the expected real return to investing in the UK linker - and the risk premium exp- $\theta_{t, n}$, the ratio of the known real return to investing in the US TIP to the expected return to investing in the UK linker (the reciprocal of the risk premium on the uncovered UK linker investment). Taking logs of both sides and letting $q=\ln Q$

8) $s_{t}=p_{t}-p *_{t}+n\left(r_{t, n}-r_{t, n}\right)+q-\vartheta_{t, n}$

We see that in first differences we must have

$$
\Delta s_{t}=\Delta\left(p_{t}-p_{t}^{*}\right)+n \Delta\left(r_{t, n}^{*}-r_{t, n}\right)-\Delta \vartheta_{t, n}
$$


A rise in the endogenous $\theta_{\mathrm{t}, \mathrm{n}}$ is an increase in the risk premium on a UK investment which is just an increase the expected excess return a US investor earns on a UK linker investment compared with the known real return he earns on a US TIP. Thus from (6) a rise in expected real return on the UK linker investment must be brought about by some combination of $a$ rise in UK - US real interest differential and a contemporaneous real appreciation of the dollar relative to the pound. An appreciation of the dollar relative to the pound today contributes to a positive expected future excess return on an inflation hedged pound investment because it sets up the expectation of a subsequent (real) depreciation of the dollar relative to the pound as is evident from (6).

When $S_{t}=\widetilde{S_{t}}$ the known real return to a US investor in investing in the US TIP is equal to the expected real return to the US investor in the UK linker. It is this sense in which $\widetilde{S_{t}}$ is the fair value of the nominal exchange rate. When the exchange rate is equal to fair value by this definition, expected real returns that can be achieved by holding inflation indexed bonds are equalized across countries. Thus our notion of fair value is related to the level of the exchange rate implied by the ex-ante real version of uncovered interest parity over a short holding period for nominal bonds. However as we illustrate below, the two are distinct ways to assess currency valuation.

\section{An Asset Pricing Interpretation}

We make a minimal number of assumptions to provide an asset pricing interpretation of Equation (7). We do not assume complete markets or a representative agent. We do not assume that we know the model, let alone the parameters, that link the present value of macro fundamentals to exchange rate valuation. Under our assumptions our framework is consistent with almost any underlying model in which inflation indexed bonds are traded. We assume that, in a global financial equilibrium, there is a functional relationship between the nominal (US dollar) price today of an asset that delivers a random dollar cash flow at some date in future (for concreteness , 10 years hence) and no cash flow at any date other than $t+n$ : 


$$
\rho_{t}=F_{t}\left(N_{t+n} ; \Omega_{t, t+n}\right)
$$

where $\Omega_{t, t+n}$ is the conditional probability distribution of the random nominal cash flow from the asset that pays off in $\mathrm{n}$ years. We specialize $F$ so that

$$
\rho_{t}=E_{t}\left(m_{t, n} N_{t+n} ; \Omega_{t, t+n}\right)
$$

So today's price of an asset with random nominal cash flow in $\mathrm{n}$ years is the conditional expectation of the product of that cash flow and the random variable $m_{t, n}$.

Assumption: $m_{t, n}$ is homogenous in the price levels $P_{t}$ and $P_{t+n}$

$$
m_{t, n}=z_{t, n} \frac{P_{t}}{P_{t+n}}
$$

This is a standard property in many asset pricing models (Cochrane (2001). For example in Lucas (1982) we have

$$
m_{t, n}=\beta^{n} \frac{U^{\prime}\left(C_{t+n}\right)}{U^{\prime}\left(C_{t}\right)} \frac{P_{t}}{P_{t+n}}
$$

Again, we do not require a representative agent, complete markets, or really any additional structure on $\mathrm{Zt,n}$. This is an intuitive restriction on nominal asset prices that says that the real price of the asset today depends upon the real value of the cash flow it delivers state by state at maturity and not the price level itself at $t+n$ itself (after, of course, controlling for factors other than the price level itself that are included in $\mathrm{Zt,n.}$.).

With this background, consider how to price a zero coupon inflation indexed bond that pays off 1 dollar in $n$ years multiplied by cumulative realized inflation over the next $n$ years. 


$$
\rho_{t}=E_{t}\left(m_{t, n} \cdot 1 \cdot \frac{P_{t+n}}{P_{t}}\right)=E_{t}\left(z_{t, n} \cdot 1\right)
$$

Or, dividing by $\rho t$

$$
1=\left\{\exp n r_{t, n}\right\} E_{t}\left(z_{t, n}\right)
$$

Where $\mathrm{r}_{\mathrm{t}, \mathrm{n}}$ is the continuous compounded known real return on the inflation indexed bond.

US investors can also obtain US dollar cash flows by investing in a UK inflation indexed bond and selling the pound proceeds for dollars in $\mathrm{n}$ years. Let $S_{t}$ be the dollar price of a pound and ${ }^{*}$ represent a UK variable. Let $\mathrm{Q}_{\mathrm{t}}=\mathrm{S}_{\mathrm{t}} \mathrm{P}_{\mathrm{t}} / \mathrm{P}_{\mathrm{t}}$ define the real exchange rate and $\mathrm{Q}$ its unconditional mean $Q=E_{t} Q_{\infty}$. Then we have

$$
S_{t} \rho^{*}{ }_{t}=E_{t}\left(m_{t, n} \cdot 1 \cdot S_{t+n} \cdot \frac{P_{t+n}^{*}}{P^{*}{ }_{t}}\right)
$$

Or dividing though:

$$
1=\exp n r_{t, n}^{*} E_{t}\left(z_{t, n} \cdot 1 \cdot \frac{Q_{t+n}}{Q_{t}}\right)
$$

With these building blocks we now derive a structural exchange rate equation that will hold in any model that seeks to describe a world in which long maturity inflation indexed bonds trade. Since such bonds trade in many countries (US, UK, France, Canada, Japan) this should apply to a large number of models. We see that

9) $S_{t}=\frac{P_{t}}{P^{*}{ }_{t}} \frac{\exp n r_{t, n}^{*}}{\exp n r_{t, n}} \frac{Q E_{t}\left(z_{t, n} \cdot 1 \cdot \frac{Q_{t+n}}{Q}\right)}{E_{t}\left(z_{t, n}\right)}$ 
Comparing with equation (6) we see that $\theta_{t, n}$ is given by

10) $\exp -\vartheta_{t, n}=\frac{E_{t}\left(z_{t, n} \cdot 1 \cdot \frac{Q_{t+n}}{Q}\right)}{E_{t}\left(z_{t, n}\right)}$

Although not necessary for what follows, we gain additional insight by looking at the log normal case in which we have equation (11).

11) $-\vartheta_{t}=\operatorname{cov}_{t, n}\left(\ln z_{t, n}, q_{t+n}-q\right)+\operatorname{var}_{t, n}\left(q_{t+n}-q\right)+E_{t}\left(q_{t+n}-q\right)$

We note that the first term in the above expression is the conditional covariance between the stochastic discount factor and real exchange rate that prevails when the zero coupon inflation linked bonds mature. This can be interpreted as a risk premium that opens up a wedge between known real return (to a US investor) of holding a long maturity TIP and the stochastic real return to a US investor of holding a UK linker. When this covariance is negative, an unhedged position in a UK linker pays off less (because of realized real appreciation of dollar relative to the pound) when the stochastic discount factor is high. Thus a positive theta corresponds to a positive risk premium on the UK linker. That is, the known real return on the US linker is less than the expected real return to the US investor, inclusive of expected appreciation of the pound, of holding a UK linker when $\theta$ is positive. An increase in the expected excess return on the UK linker will require some combination of an increase in $\mathrm{r}^{*} \mathrm{t}, \mathrm{n}-\mathrm{r}_{\mathrm{t}, \mathrm{n}}$ and $\mathrm{a}$ jump appreciation of the dollar.

In what follows we shall assume for ease of exposition that expected deviations from PPP at a 10 year horizon are sufficiently close to zero so as to be ignored. Importantly, however, researchers who have a view on long horizon PPP deviations can include that view directly and use it as an input to the accounting framework we develop below. Thus, in what follows, we shall refer to $\theta_{\mathrm{t}, \mathrm{n}}$ as the risk premium. 
It is worth noting that the complete markets assumption which we don't require to derive (7) or (9) would put a number of additional restrictions on the joint behavior of exchange rates and bond yields, both inflation indexed and nominal. For example, under complete markets, Backus et. al. (2001) show that

12) $\frac{S_{t+1}}{S_{t}}=\frac{m_{t, 1}}{m^{*}}$

We see that in our notation this would also imply

13) $\frac{Q_{t+1}}{Q_{t}}=\frac{z_{t, 1}}{z^{*}{ }_{t, 1}}$

These are elegant, powerful implications but we do not impose them on the data or use them to interpret real time exchange rate fluctuations.

\section{Comparison with the Literature}

Building on earlier work by Hansen and Hodrick (1980) and Cumby and Obstfeld (1981), Fama (1984) is the classic study of the risk premium to holding a long position in a foreign currency nominal bond for one period (but see also Clarida, Davis, and Pedersen (2009) for a recent analysis of what can - and can't be leaned - from a Fama regression). In the literature (see Engel 2010 for a review and extension) this concept of the risk premium is usually defined by the first order log approximation

\section{4) $r p_{t, 1}=E_{t} s_{t+1}-s_{t}+i_{t, 1}^{*}-i_{t, 1}$}

where lower case i denotes the short term nominal interest rate. There is of course a long and proud tradition in the international finance literature, beginning with Frankel (1978), of empirically relating real exchange rates to real interest differentials (Shafer and Loopesko (1983); Campbell and Clarida (1987); Clarida - Gali (1994) are early examples). For the most part, this literature pre dates the widespread introduction of long maturity 
inflation indexed bonds and of necessity solves forward the real version of the deviations from UIP equation.

$$
r p_{t, 1}=E_{t} q_{t+1}-q_{t}+e r_{t, 1}^{*}-e r_{t, 1}
$$

where $e r_{t, 1}=i_{t, 1}-E_{t} t t, 1$ is the ex ante short term real interest rate on nominal bonds at home and similarly abroad. Solving forward and assuming $\ln Q_{t}$ is stationary we obtain (see Engle (2010) for a lucid discussion and Brunermeier, Nagel, and Pedersen (2008) for an interpretation of the forward solution for the nominal exchange rate under uncovered interest parity):

16) $\quad q_{t}=\sum_{i=0}^{\infty}\left({ }_{t} e r *_{t+i, 1}-{ }_{t} e r_{t+i, 1}-\mu\right)-\sum_{i=0}^{\infty}\left({ }_{t} r p_{t+i, 1}-\lambda\right)+E \ln Q_{\infty}$

Note that convergence of these non-discounted present value equation requires the unconditional mean of the ex-ante real rate differential $\mu$ to equal the mean of the Fama risk premium $\lambda$. Comparing terms we see

17) $\vartheta_{t, n}=\sum_{i=0}^{n} r p_{t=I, 1}-\lambda+\left\{n\left(r_{t, n}^{*}-r_{t, n}\right)-\sum_{i=n}^{n}\left({ }_{t} e{ }^{*}{ }_{t+i, 1}-{ }_{t} e r_{t+i, 1}-\mu\right)\right\}+q-E \ln Q_{t+n}$

where for concreteness we suppose that

$$
\sum_{i=n}^{\infty}\left({ }_{t} e{ }^{*}{ }_{t+i, 1}-{ }_{t} e r_{t+i, 1}-\mu\right)=0
$$

and similarly for the Fama premium after $\mathrm{n}$ periods. We see that our measure of the risk premium $\theta_{t, n}$ is the sum of three terms: the $\mathrm{n}$ period sum of the expected Fama risk premiums; the difference (in brackets) between home and foreign long maturity inflation indexed bond returns and the expected real returns to rolling one period nominal bonds; and a Jensen's inequality term. We can re arrange to obtain an equation relating the observed long maturity inflation indexed yield differential to the present value of ex ante (un indexed) real short term interest rates differentials and the present value of the Fama risk premiums 


$$
n\left(r *_{t, n}-r_{t, n}\right)=\sum_{i=0}^{n}\left({ }_{t} e{ }^{*}{ }_{t+i, 1}-{ }_{t} e r_{t+i, 1}\right)+\theta_{t, n}-\sum_{i=0}^{n} r p_{t+i, 1}+E \ln Q_{t+n}-q
$$

There are two approaches that have been used to turn (16) into a model of exchange rates and real interest rates. Campbell and Clarida (1987), Clarida and Gali (1994) and recently Engel (2010) estimate time series models of ex ante short term real rate differentials and use a vector auto regression to forecast the infinite sum of ex ante real differentials. Of course the reliability of this approach depends on the linear time series models being a good proxy for expected future ex ante real interest rates. An alternative approach (Shafer and Loopesko (1983)) relies on the expectations hypothesis of the term structure to substitute out for the ex ante nominal short rate differentials and to rely on surveys or time series models of inflation to recover an estimate of long term ex ante real rate differentials.

$$
\sum_{i=0}^{n}\left({ }_{t} e r_{t+i, 1}^{*}-{ }_{t} e r_{t+i, 1}\right)=n\left(I^{*}{ }_{t, n}-I_{t, n}\right)-\sum_{i=0}^{n}\left({ }_{t} \pi_{t+i, 1}^{*}-{ }_{t} \pi_{t+i, 1}\right)+t p_{n}
$$

Note that for this approach to work, not only must a model of inflation expectations be estimated, but one must assume a constant term premium. An advantage of our approach outlined above is that, under the rather modest assumption that the pricing kernel is homogeneous in price levels, we can use observation on inflation indexed bond yields directly to recover the fair value of nominal exchange rates as well as econometric free estimates of the risk premium relevant for pricing inflation indexed yield curves and currencies. 
Our data set is comprised of daily observations on spot exchange rates, inflation indexed bond yields, and monthly observations on consumer price indexes for the US, UK, and Euro area for the period January 2001 through January 2011 and for Japan since December 2004 shortly after inflation indexed bonds were introduced. We convert monthly CPI levels to daily observations via interpolation. Given the low and relative stable rate of inflation for these countries over this period, the approximation of the unobserved daily inflation differential with the observed per day monthly average inflation differential introduces measurement error, but this error is small relative to the observed daily volatility of exchange rates and inflation indexed bond yields.

Our theoretical model is derived in terms of the yields on inflation indexed zero coupon bonds. Inflation indexed bonds are typically issued in coupon form. However, in the US there is a market in which inflation indexed coupon Tips are stripped of their coupons and trade in zero coupon form. In our empirical analysis we will use daily data on constant 10 years to maturity yields on zero coupon Tips provided by Barclays. For the UK, we use the data on zero coupon linker yields provided by the Bank of England. For the Euro, we use estimates of the zero coupon inflation indexed yield curve for French and German inflation indexed bonds provided by Morgan Stanley. For Japan, no data on zero coupon inflation indexed yields could be found so we use the observed yield on coupon bearing inflation indexed bonds.

One final point to discuss is how we calibrate the constant term in Equation (7) for fair value. This constant term is not important for much of what we do since we will often seek to account for percent changes in observed nominal exchange rates in terms of percent changes in fair value and changes in the risk premium. For these exercises, the constant drops out. However, in drawing the some of the graphs we will wish to preserve the levels information, and will select the constant term equal to the average real exchange rate during the sample period depicted. 


\section{Empirical Results}

We now use the framework developed above to interpret the behavior of the Euro, Pound, and Yen exchange rates over the past 10 years. There are no econometric estimates to present because our framework (Equation 7) provides day by day a real time decomposition the change in the exchange into the change in the fair value and the change in risk premium. Our framework allows - indeed we expect to find periods in which shocks to the risk premium are large and die out slowly while there may be other periods in which exchange rate movements, contrary to the original Meese-Rogoff (1983) finding that exchange rate changes are difficult to explain even given even ex post realizations of fundamentals, are well accounted for by shifts in our measure of fair value derived above.

We present our main findings in a series of charts. For each exchange rate, the charts will help us to identify as well as quantify the importance of shocks to fair value and shocks to the risk premiums in accounting for exchange rate fluctuations over different periods as well as over various horizons of interest. As our sample includes the global financial crisis and its aftermath (at least through January 2011!), we are particularly interested to determine and quantify the shifts in risk premium and fair value that occurred over this period. 


\section{Chart 1}

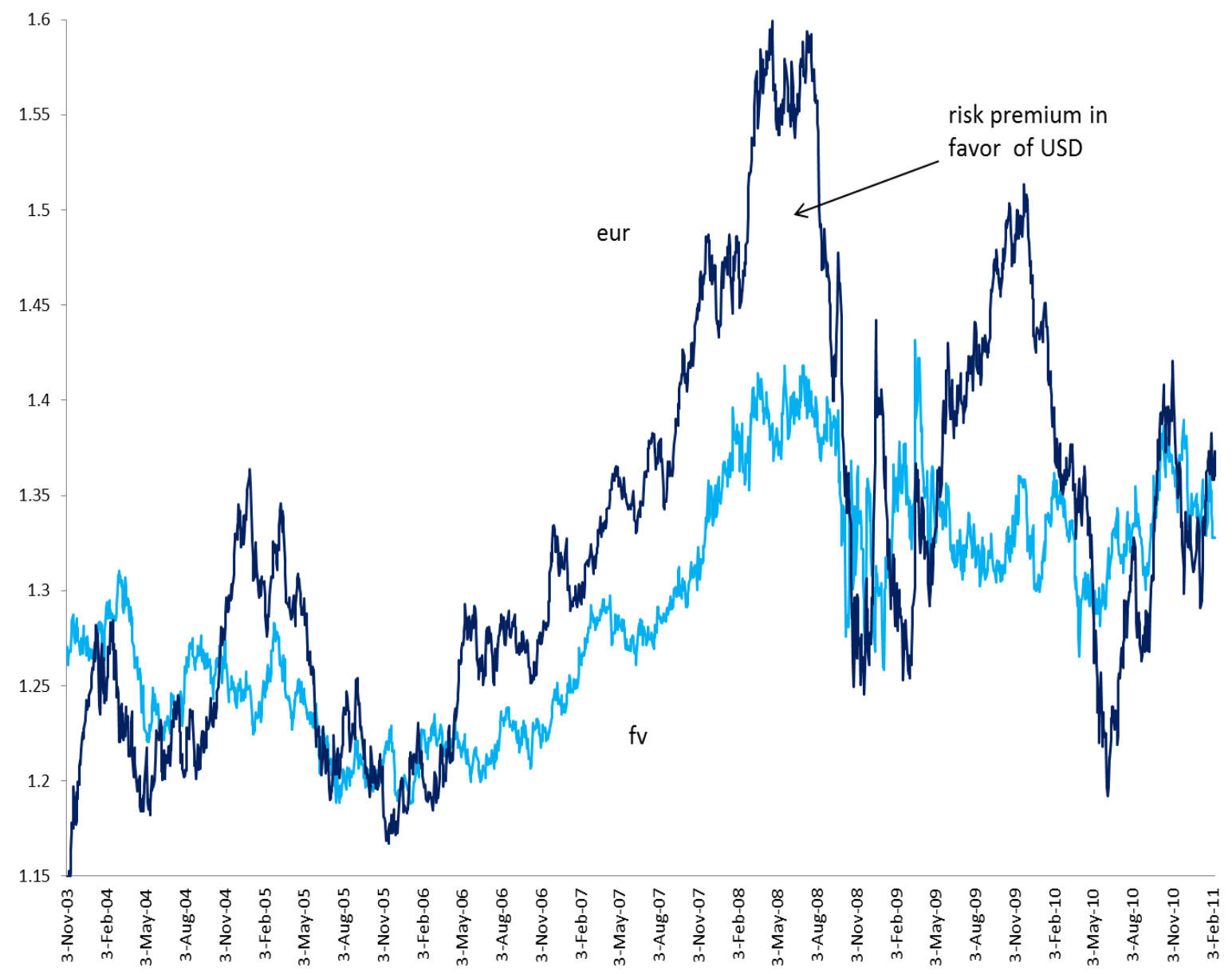

In Chart 1, and in all subsequent charts, the dark blue line depicts the spot exchange rate, in this case the US dollar price of a Euro, the aqua blue line is the fair value defined by Equation 11. The amount by which the exchange rate EUR exceeds FV measures the risk premium in favor of the USD that is reflected in the EUR spot exchange rate. This corresponds

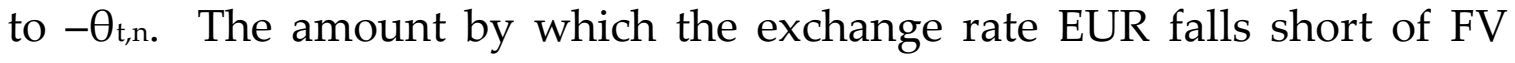
measures the risk premium in favor of the EUR that is reflected in the EUR spot exchange rate. This corresponds to $\theta_{\mathrm{t}, \mathrm{n}}$.

Our framework we believe provides a compelling qualitative as well as a plausible quantitative account of the swings in Euro exchange rate since 2005. As can be seen from the chart, the broad move in the Euro from 1.25 in the summer of 2005 to 1.45 in the spring of 2008 is well 
accounted for, both in direction and in magnitude, by the rise in the fair value during that period. According to our model, the next move in the Euro from 1.45 to the 'brutal' level of 1.60 reached in the summer of 2008 was due almost entirely an equal move in the risk premium, in favor of the dollar and thus against the Euro.

Since the onset the global financial crisis in September 2008, movements in the Euro have been dominated by fluctuations in risk premium with fair value fluctuating in a rather narrow range centered at roughly 1.37. In October 2008, our measure of the risk premium swings in favor of the Euro (e.g. it appreciated the dollar price of the Euro to such an extent it set up the expectation of a deprecation and thus capital gain on a Euro investment). The risk premium swings back in favor of the dollar in the second half of 2009 as the dollar depreciates in tandem with the Fed's quantitative easing programs announced in March of that year. Since 2010, our framework indicates that the foreign exchange market has required a positive risk premium to hold the Euro. This period of course coincides the crisis in the Euro periphery.

Of course, it is important to confirm that the visual impression conveyed by the chart is evident in the actual empirical correlation between the Euro exchange rate and our measure of fair value.

Chart 2: Correlation in Daily Changes in Eur and $F V$ (60 day window)

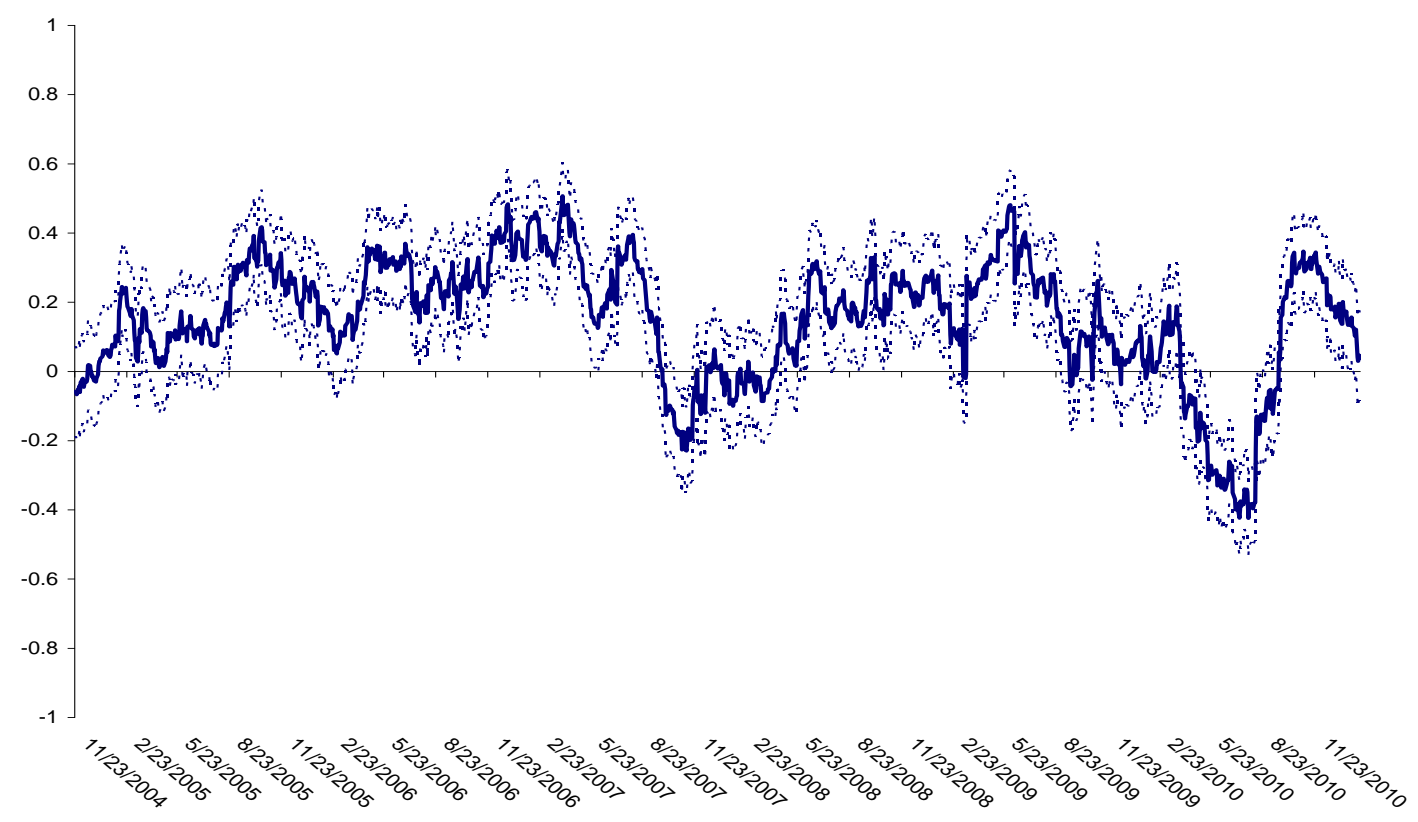


Chart 2 depicts the correlation (over rolling 60 day windows) between daily changes in Euro exchange rates and daily changes in our measure of fair value which of course is dominated by daily changes in real interest rate differentials between Europe and US inflation indexed bonds. We see that periods in which the correlation is in the range of 0.3 to 0.4 are not uncommon. We also see that in periods in which shocks to the risk premium are seen to dominate, the correlation between the Euro and fo falls to zero or is even negative. One is tempted to identify periods in which the exchange rate is well accounted for by movements in fo (such as 2005 to 2008 in Chart 1) as periods in which 'fundamentals' mostly matter for exchange rate determination, in contrast to periods since September 2008 in which 'fundamental' are pushed aside and 'risk aversion' appears to take over. But within the strict logic of our framework, this temptation would not be justified. Fundamentals may drive the risk premium as well, but without imposing much more additional structure on $m t, n$ we can't really say more. However, unlike the traditional approach (Fama (1984)) in which an unobserved currency risk premium must be inferred by extracting the forecastable component from realized returns on currency carry trades, our framework provides an econometric free measure of the relevant risk premium given observed yields on inflation indexed bonds and the spot exchange rate.

Chart 3

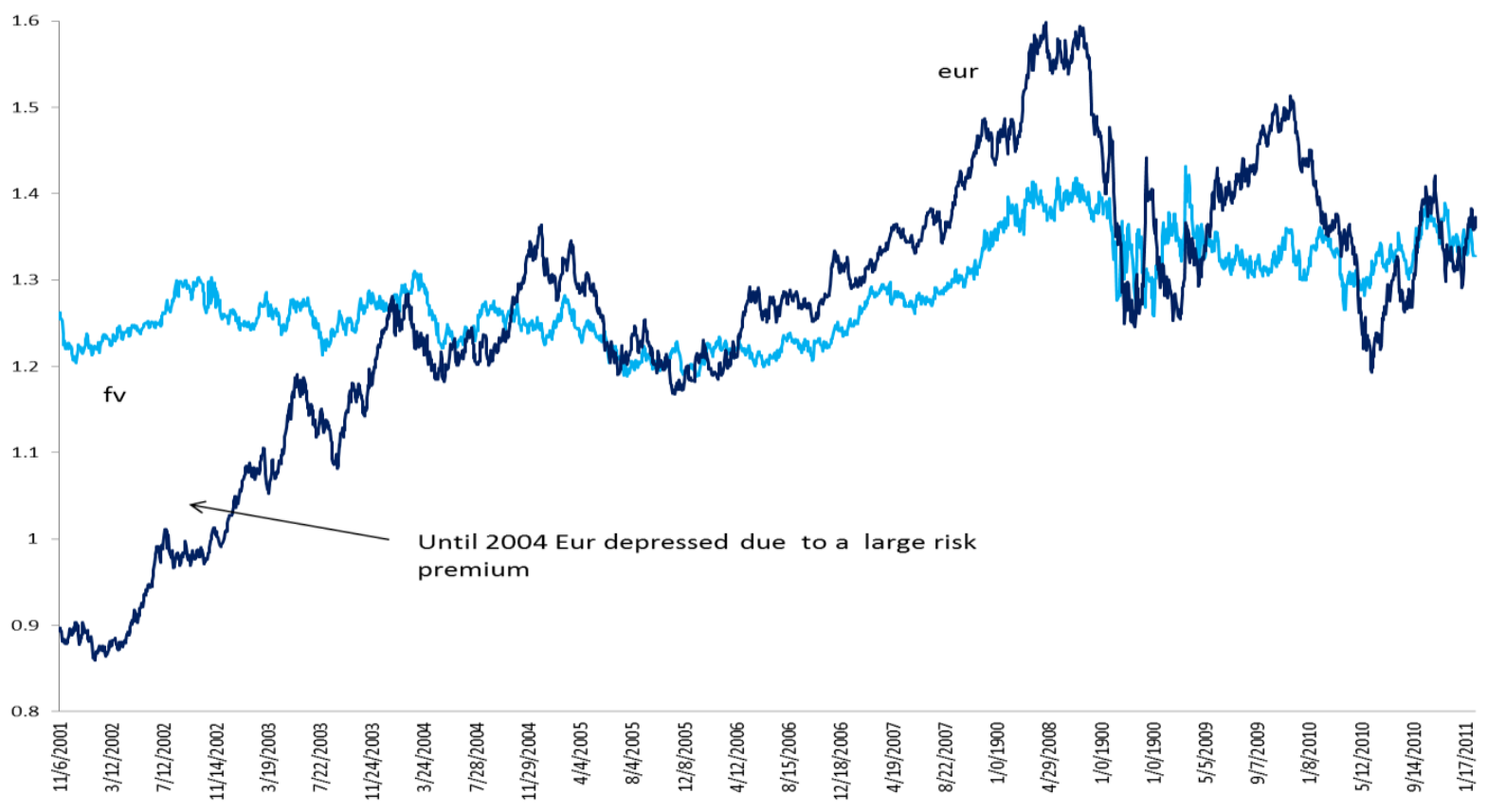




\section{Pound}

\section{Chart 4}

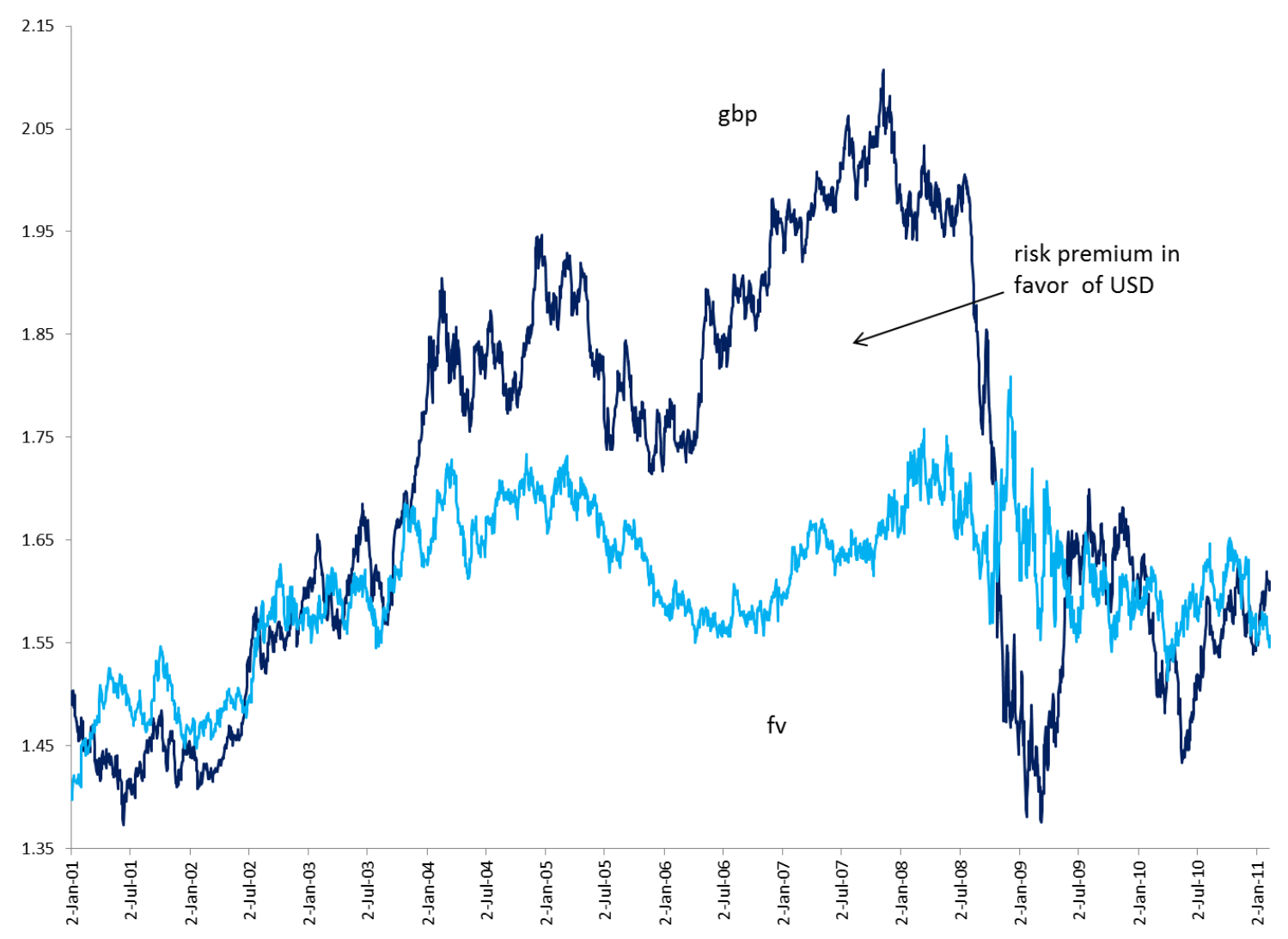

Chart 4 depicts our decomposition of the GBP exchange rate into is fair value and risk premium components. From 2001 through summer of 2005 , the appreciation of the pound from 1.50 to 1.75 is almost fully accounted for by an equal rise in our estimate of fair value from the inflation indexed bond market. However, our framework accounts for the subsequent move up from 1.75 to 2.05 reached in January 2008 almost entirely by the emergence of a substantial risk premium in favor of the dollar (i.e. a risk premium that set up expectation of a higher return on a US inflation linked bonds). This risk premium is eliminated and shifts in favor of the GBP in September 2008 and has remained in place since. Since 2009, our estimate of fair value has stayed in a narrow range centered around 1.65 . 
Chart 5: Correlation in Daily Changes in GBP and FV (60 day window)

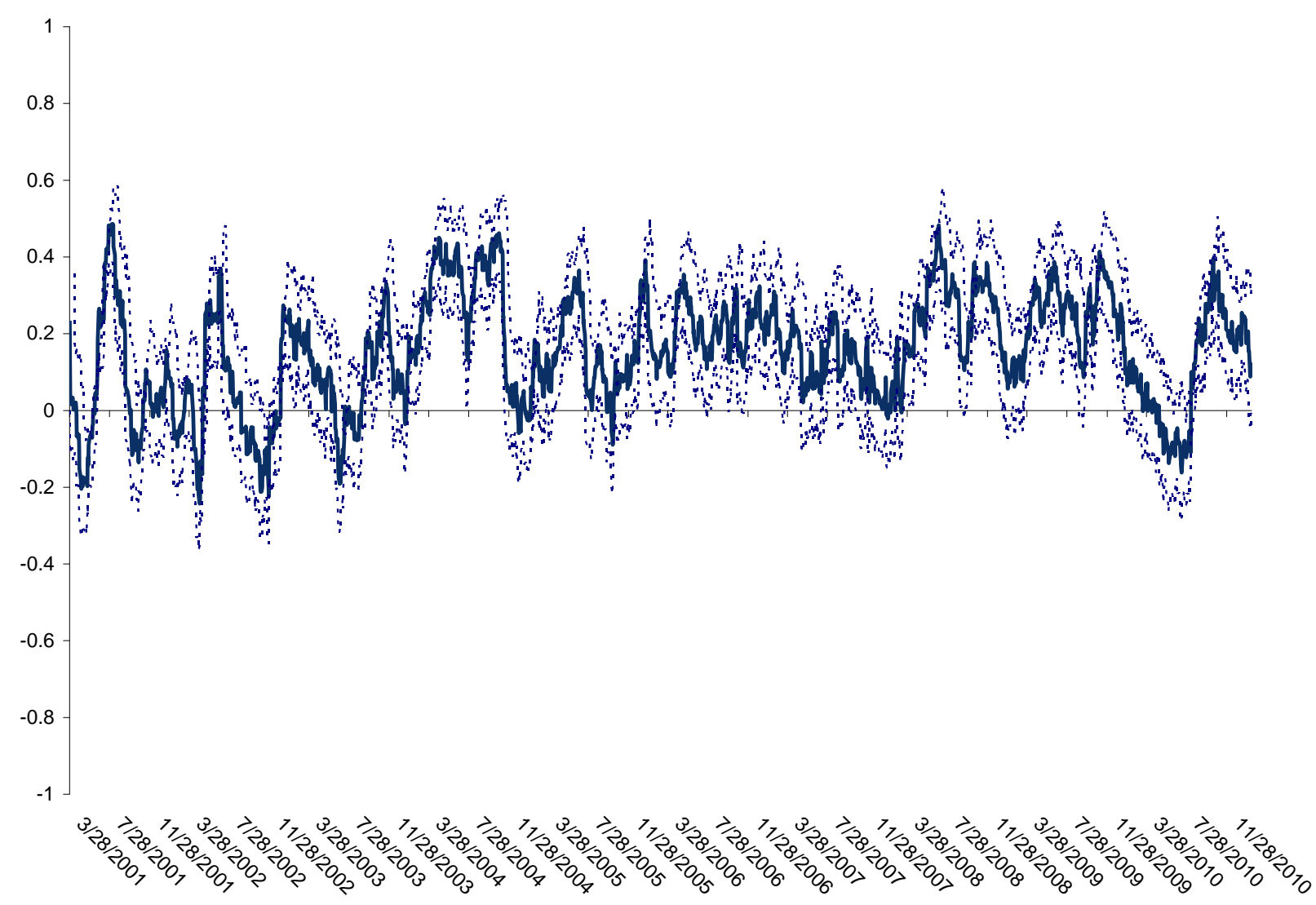

Chart 5 depicts the correlation (over rolling 60 day windows) between daily changes in GBP exchange rates and daily changes in our measure of fair value Again we see that periods in which the correlation between daily changes is in the range of 0.3 to 0.5 are not uncommon. We also see that in periods in which shocks to the risk premium are seen to dominate, the correlation between the GBP and fo falls to zero or is even negative. The implies that large shocks to the risk premium in favor of the pound (or in Chart 1 the Euro) tend to require both depreciations of the exchange rate relative to the dollar - to set up the expectation of future appreciation - as well as a rise in the real interest rate differential in favor of the pound (or the Euro). 


\section{Chart 6}

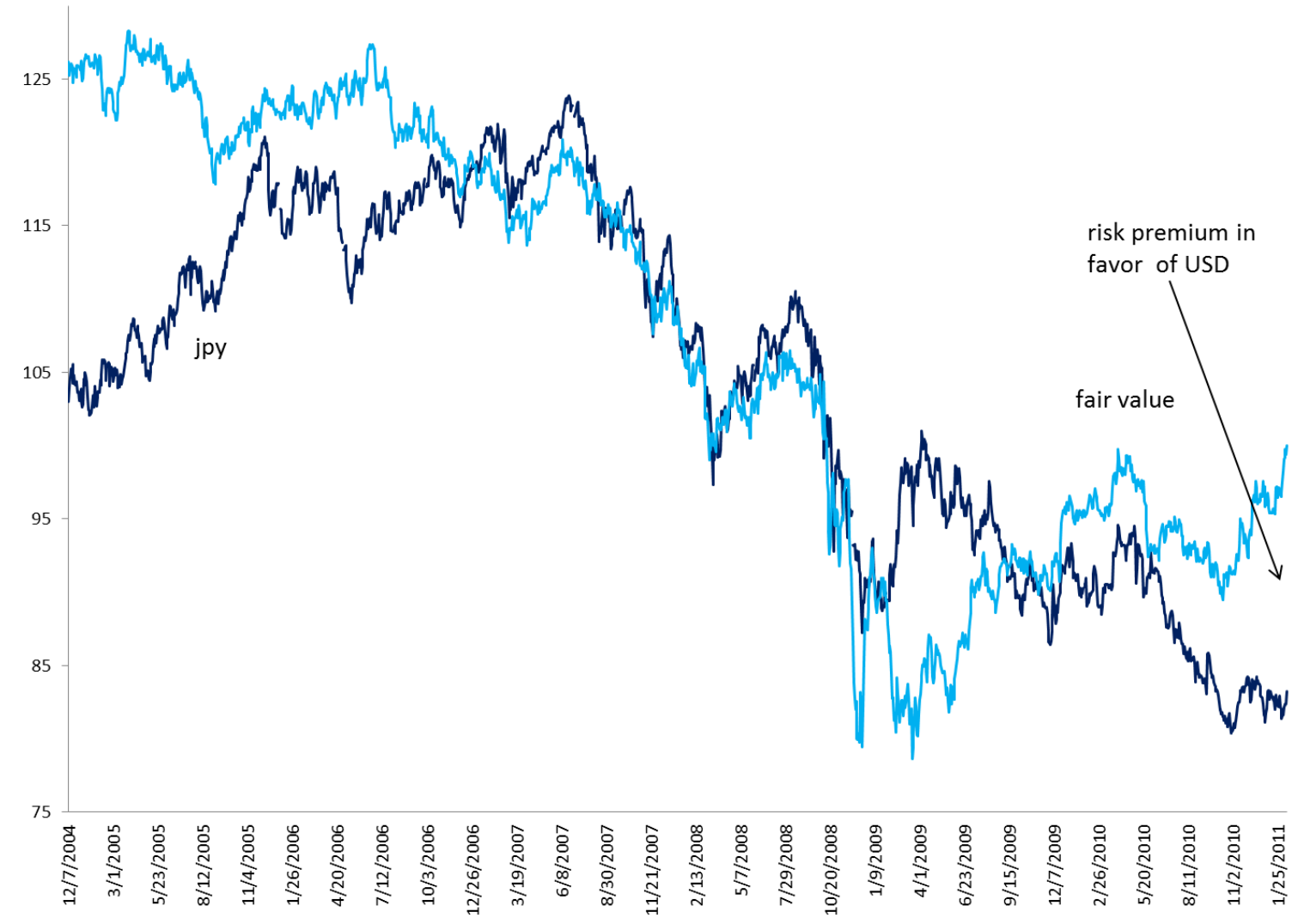

Chart 6 depicts our decomposition of the JPY exchange rate into is fair value and risk premium components. From 2005 through summer of 2010, the appreciation of the yen from 120 to 88 is almost fully accounted for by an equal shift in our estimate of fair value. During most of this period there was also a modest and not very volatile risk premium in favor of the yen. This risk premium widened in the fall of 2008 but was almost entirely eliminated by the summer of 2009. Since that time, we estimate that a risk premium in favor of the dollar opened up as the yen continued to appreciate notwithstanding a shift in fair value in the direction of a weaker yen. Our last data point is February 11, 2011. Finally Chart 7 confirms that, if anything, changes in the yen and our measure of fair value have been more highly correlated than we found for the Euro and the pound. 
Chart 7: Correlation in Daily Changes in JPY and $F V$ (60 day window)

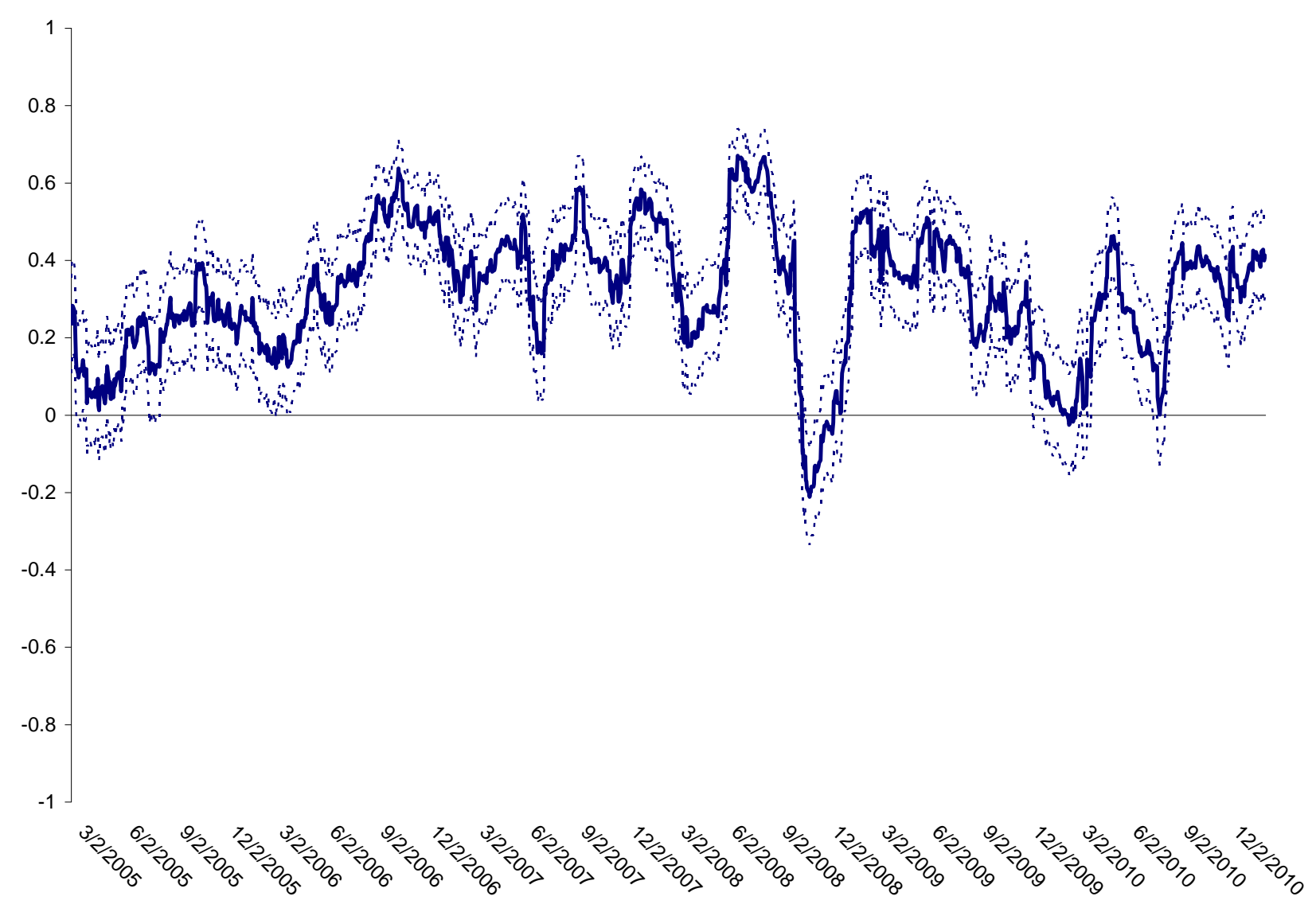

$V$. Regressions of $\left(r^{*} t, n-r_{t, n}\right)$ on $\Delta \theta_{t, n}$ and $\Delta s_{t}$ on $\Delta \theta_{t, n}$

Recall in our framework, period by period, we have

19)

$$
\Delta s_{t}=\Delta\left(p_{t}-p *_{t}\right)+n \Delta\left(r_{t, n}-r_{t, n}\right)-\Delta \vartheta_{t, n}
$$

A positive shock to $\theta_{\mathrm{t}, \mathrm{n}}$ is an increase in the risk premium on a UK investment which increases the expected excess return a US investor earns on a UK investment. This must be brought about by some combination of a rise in UK - US inflation indexed yield differential and or an appreciation of the dollar relative to the pound. In daily data, we can recover $\Delta \theta_{t, n}$ since every other term in equation (19) is observable (up to the negligible error in approximating unobserved daily inflation differentials with the per day monthly average inflation differential). We can thus for 
each country regress $n\left(r_{t, n}^{*}-r_{t, n}\right)$ on $\Delta \theta_{t, n}$ and $\Delta \mathrm{st}_{\mathrm{t}}$ on $\Delta \theta_{t, n}$ to quantify how much of a change in the risk premium is on average reflected in indexed bond yields and how much is reflected in the nominal exchange rate. When we do so, we find that a striking feature in the data is that, for all three exchange rates, roughly half of a given rise in the risk premium is reflected in a rise in the inflation indexed bond return differentials in favor of the foreign country and the remaining half is reflected in an appreciation of the dollar. These regression results are presented below in the following charts. We note that while constant terms are included in each regression, none is statistically significant. In each regression the sample is daily $1 / 1 / 2005$ to 10/16/2012. We do not make any inference of cause and effect. All three variables are endogenous. But any macro model of risk and return in the foreign exchange market in a world with inflation indexed bonds should endeavor to match these correlations. 

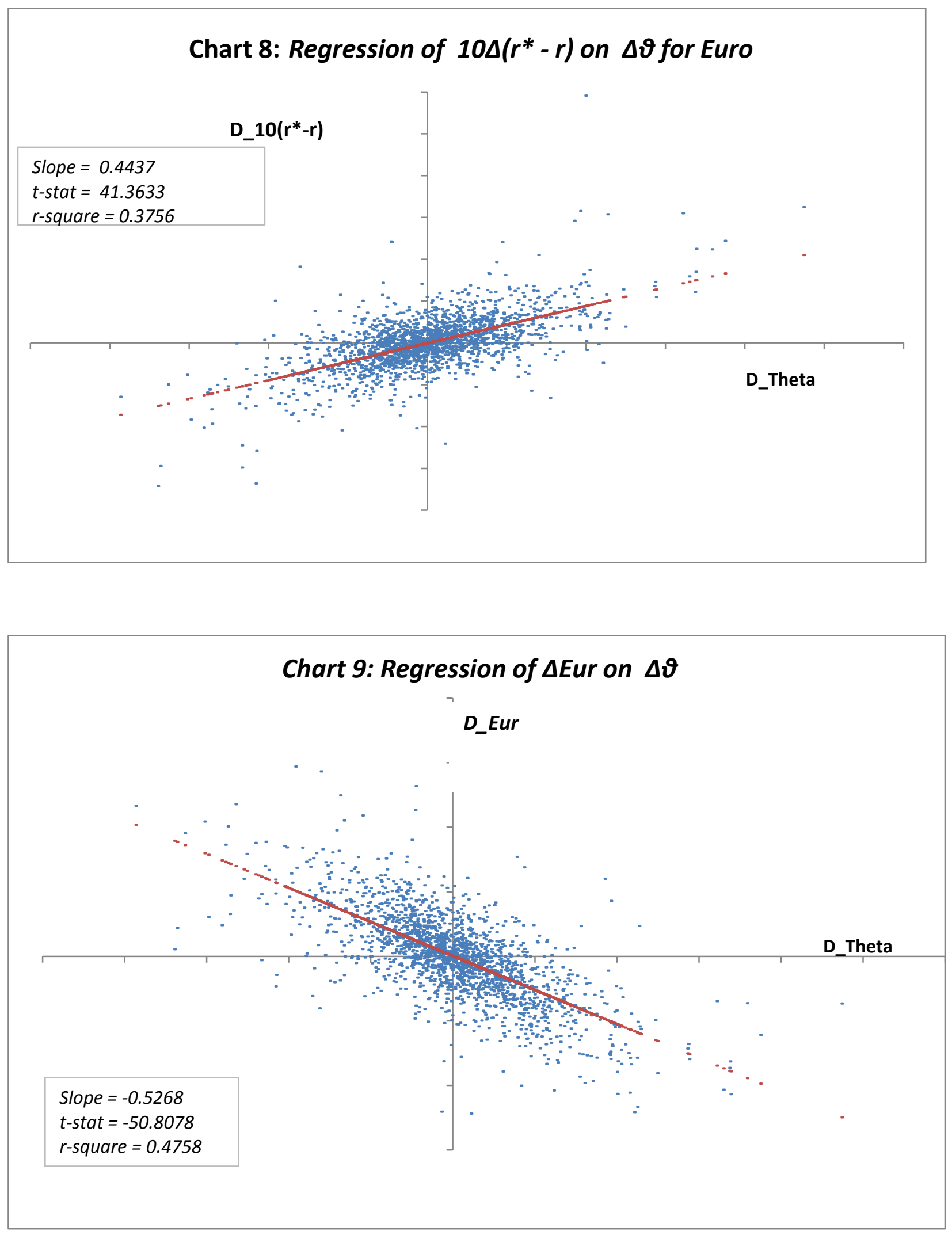

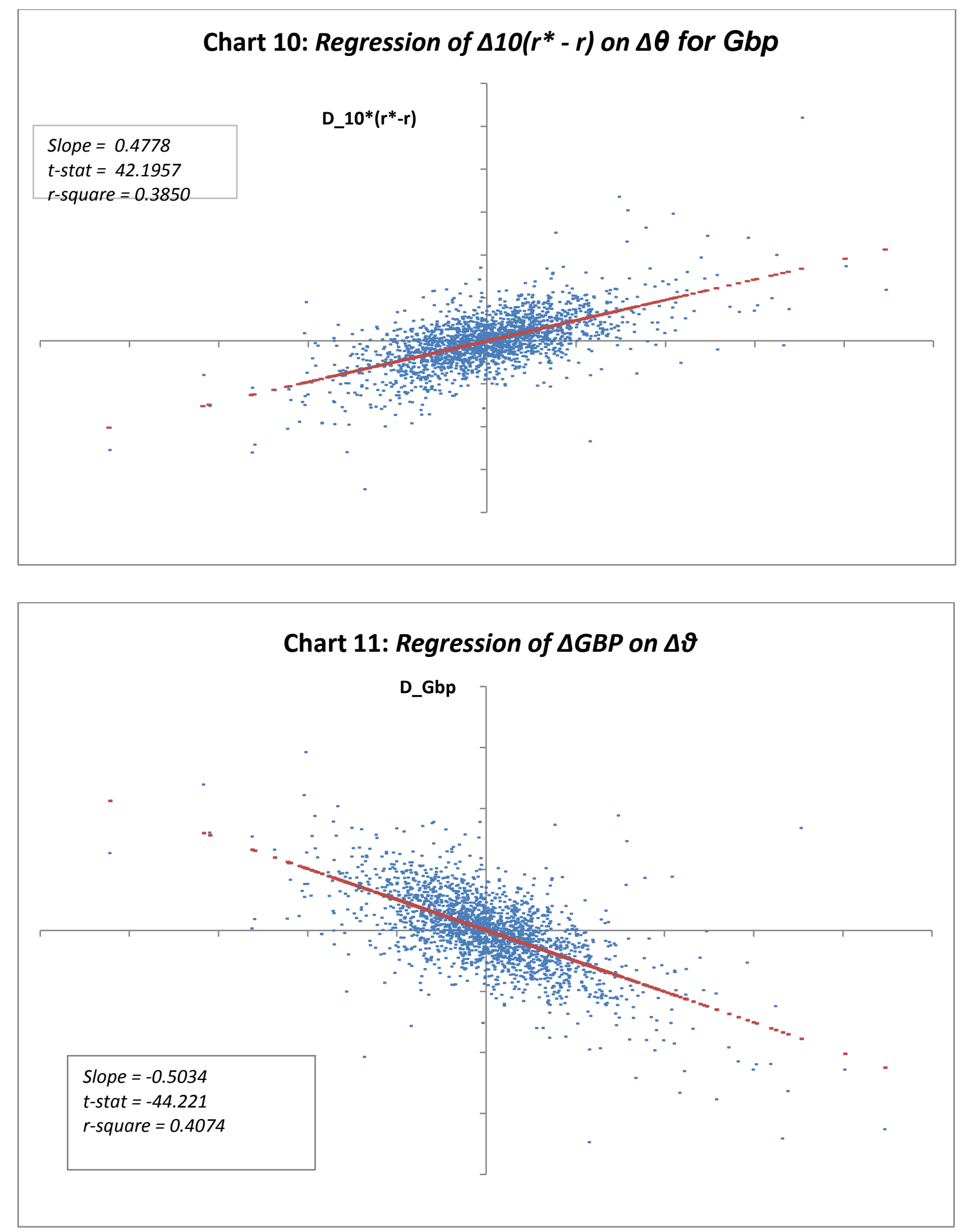

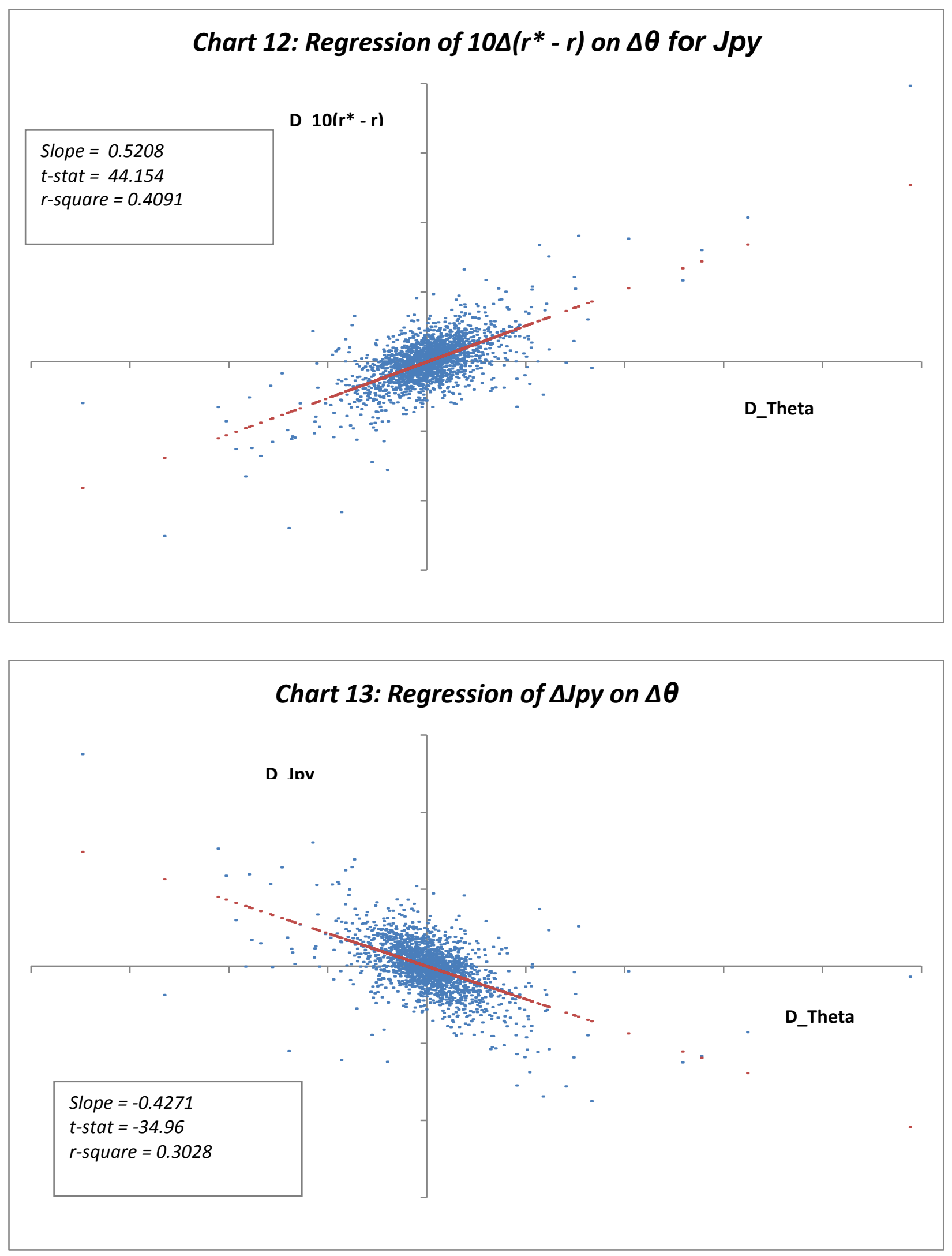
VI. Concluding Remarks

This paper has derived a novel structural relationship between the nominal exchange rate, national price levels, and observed yields on long maturity inflation - indexed bonds. This relationship can be interpreted as defining the fair value of the exchange rate as well as an empirically observable measure of the risk premium that can open up a wedge between the observed level of the nominal exchange rate and its fair value. We take our theory to the data to study high frequency, real time decompositions of pound, euro, and yen exchange rates into their fair value and risk premium components and find that the relative importance of these two factors varies depending on the sub sample studied. However, sub samples in which, contrary to the Meese-Rogoff (1983) puzzle, 30 to 60 percent of the fluctuations in daily exchange rate changes are explained by contemporaneous changes in fair value are not uncommon. We also find that a striking feature in the data is that, for all three major exchange rates in our study, on average roughly half of a given rise in the risk premium is reflected in a rise in the inflation indexed bond return differentials in favor the foreign country and the remaining half is reflected in an appreciation of the dollar. We do not make any inference of cause and effect. All three variables are endogenous. But any macro model of risk and return in the foreign exchange market in a world with inflation indexed bonds should endeavor to match these correlations.

A priority for future research is to investigate the dynamic relationship between shocks to the observable $\Delta \theta_{\mathrm{t}, \mathrm{n}}$ and subsequent changes in the spot exchange rate $\Delta s_{t+j}$. We know from Section $\mathrm{V}$ that on average in our sample a rise in $\Delta \theta_{\mathrm{t}, \mathrm{n}}$ is contemporaneously associated with a rise in $\left(r_{t, n}^{*}-r_{t, n}\right)$ and a decline (appreciation) in $\Delta \mathbf{S t}_{\mathrm{t}}$, and we know from the Fama result that future changes in the spot rate $\Delta \mathrm{st}_{\mathrm{t}+\mathrm{j}}$ are positively correlated with the short term nominal differential $i^{*}{ }_{t, 1}-i_{t, 1}$. Modeling empirically the dynamic not just the contemporaneous interaction between the exchange rate, our measure of the risk premium, and the (macro) factors orthogonal to risk that account for interest rate differentials promises to add to our knowledge of risk and return in the currency market. 


\section{References}

Backus, D. S. Foresi, C. Telmer," Affine Models of Currency Pricing," Journal of Finance 2001.

Brunermeier, Nagel, and Pedersen, "Carry Trades and Currency Crashes," NBER Macro Annual 2008.

Campbell, J. and R. Clarida (1987), The Dollar and Real Interest Rates, Carnegie-Rochester Conference on Public Policy, 1987.

Canzoneri, M. and H. Dellas, "Real Interest Rates and Central Bank Operating Procedures," Journal of Monetary Economics, 1998.

Clarida. R., "Get Real: Interpreting Nominal Exchange Rate Fluctuations," International Journal of Central Banking, January 2012.

Clarida, R. and J. Gali, "Sources of Real Exchange Rate Fluctuations: How Important are Nominal Shocks?", Carnegie-Rochester Conference on Public Policy, (42) 1994.

Clarida, R., J. Davis, and N. Pedersen, "Currency Carry Trade Regimes: Beyond the Fama Regression," Journal of International Money and Finance, 2009.

Cochrane, J., Asset Pricing, Princeton, 2001.

Cumby, R. and M. Obstfeld, "A Note on Exchange Rate Expectations and Nominal Interest Differentials," Journal of Finance, 1981.

Engel, C. Real Exchange Rates, Real Interest Rates, and Risk Premium , mimeo, December 2010.

Engel, C. and K. West, "Global Interest Rates, Currency Returns and the Real Value of the Dollar" AER Papers and Proceedings, 2010.

Engel, C. N. Mark, and K. West, “Exchange Rate Models are Not as Bad as You Think," NBER Macroeconomics Annual 2007.

Fama, E., "Forward and Spot Exchange Rates", Journal of Monetary Economics 1984

Frankel (1979), "On The Mark: A Theory of Floating Exchange Rates Based on Real Interest Differentials," American Economic Review 69, no. 4, September 1979, 601-622

Hansen, L. and R. Hodrick, "Forward Exchange Rates as Optimal Predictors of Future Spot Rates," Journal of Political Economy, 1980.

Shafer, J. and B. Loopesko, 'Floating Exchange Rates after 10 Years," Brookings Papers on Economic Activity, 1983.

Meese- Rogoff (1983), Empirical Exchange rate Models of the Seventies: Do They Fit Out of Sample?," Journal of International Economics, 1983. 